\title{
EEN VREEMDELINGEN-LABORATORIUM VOOR BIOLOGISCH ONDERZOEK IN SURINAME. DOOR
}

\author{
GEROLD STAHEL, \\ Directeur van het Landbouwproefstation \\ EN
}

A. REYNE

Gouvernements-entomoloog.

Laat onze wetenschappelijke mannen op het gebied van natuuronderzoek zich wijden aan onze koloniën en zeer zeker ook aan het in dit opzicht zoo verwaarloosde Suriname.

F. W. VAN EDEN 1896.

In het rapport, dat de Utrechtsche Hoogleeraar F. A. F. C. Went in 1902 over de "Landbouwtoestanden in de Kolonie Suriname" uitbracht, werd voorgesteld, om in het nieuw op te richten Landbouwproefstation een kamer te reserveeren, ten einde vreemdelingen in de gelegenheid te stellen, om op botanisch en zoölogisch gebied te kunnen werken.

Bij de oprichting van het Landbouwproefstation hield Dr. C. J. J. van Hall met dezen wensch van Prof. Went rekening. Eén van de kamers van het nieuwe gebouw werd voor een vreemdelingen-laboratorium gereserveerd. Daar echter in 1904 en 1905 van deze inrichting geen gebruik werd gemaakt, werd in 1906 de hiervoor bestemde kamer voor andere doeleinden in beslag genomen. Dit feit is misschien ten deele de oorzaak geweest, dat tot heden door vreemde biologen van de gelegenheid nog geen gebruik werd gemaakt om op het Landbouwproefstation te komen werken. 
Verscheidene plant- en dierkundigen (A. Pulle, J. Boldingh, W. C. van Heurn, D. H. Campbell) hebben na Went de kolonie bezocht, maar deze hebben zich meer in het bizonder met het verzamelen van planten en dieren bezig gehouden. De eenige vreemdeling, die gedurende de laatste 18 jaren in Suriname op biologisch gebied heeft gewerkt, is J. B. Rorer van Trinidad. Hij heeft echter zijn onderzoek over den veroorzaker van de krullotenziekte op een plantage uitgevoerd en miste dus de voordeelen van een goed ingericht laboratorium. Maar juist Rorer toonde, hoe nuttig het bezoek van vreemde biologen voor de Kolonie kan zijn; we danken toch aan zijn onderzoek in hoofdzaak de ontdekking van den veroorzaker der krullotenziekte in de cacao.

$\mathrm{Nu}$ echter het nieuwe gebouw van het Departement van den Landbouw buiten een herbariumkamer ruime werkplaatsen biedt ook voor vreemde biologen, wenschen we de Nederlandsche en ook buitenlandsche biologen bekend te maken met de faciliteiten, die ze bij een bezoek aan de Kolonie voor een eventueel onderzoek kunnen vinden.

Behalve een werkplaats met gas en waterleiding vindt de bioloog hier het noodige aan glaswerk en chemicaliën, verder microtoom, balansen, sterilisator, thermostaat, een microphotographisch apparaat van Zeiss, een donkere kamer, etc. Van onze bibliotheek met talrijke natuurwetenschappelijke werken en tijdschriften zal spoedig een catalogus verschijnen.

Paramaribo ligt op $5^{\circ} 50^{\prime}$ N.B. en $55^{\circ} 12^{\prime}$ W.L. aan de Suriname rivier, 10 K.M. van de kust verwijderd. De stad ligt in het breede alluviale kustland, dat zich 40-60 K.M. diep in het binnenland uitstrekt. Gedurende den regentijd staat dit kustland met uitzondering van de schulpen zandritsen, die evenwijdig met de kust verloopen, één tot meerdere voeten diep onder water. Wat het klimaat betreft komt deze streek vrijwel overeen met het naburige Amazone-gebied. Enkele cijfers aangaande het klimaat van Suriname mogen hieronder volgen. 


\begin{tabular}{l|c|c|c|c|c}
\hline \hline & $\begin{array}{c}\text { Tempera- } \\
\text { tuur gem. } \\
\text { (19 jaar). }\end{array}$ & $\begin{array}{c}\text { Max. Temp. } \\
\text { gem. } \\
\text { (19 jaar). }\end{array}$ & $\begin{array}{c}\text { Min. Temp. } \\
\text { gem. } \\
\text { (19 jaar). }\end{array}$ & $\begin{array}{c}\text { Zonneschijn } \\
\text { in \% gem. } \\
\text { (2 jaar). }\end{array}$ & $\begin{array}{c}\text { Neerslag } \\
\text { in m.M., } \\
\text { gem. } \\
\text { (63 jaar). }\end{array}$ \\
\hline Januari & 25.9 & 29.1 & 22.0 & 38 & 219 \\
Februari & 26.0 & 29.3 & 21.8 & 46 & 178 \\
Maart & 26.2 & 29.3 & 22.3 & 32 & 216 \\
April & 26.5 & 29.6 & 22.6 & 32 & 232 \\
Mei & 26.5 & 29.5 & 22.8 & 29 & 310 \\
Juni & 26.4 & 29.6 & 22.6 & 38 & 294 \\
Juli & 26.7 & 30.3 & 22.4 & 52 & 221 \\
Augustus & 27.4 & 31.3 & 22.9 & 66 & 148 \\
September & 28.0 & 32.1 & 23.1 & 61 & 68 \\
October & 28.0 & 32.2 & 22.8 & 64 & 69 \\
November & 27.4 & 31.4 & 22.7 & 54 & 123 \\
December & 26.3 & 30.2 & 22.2 & 37 & 216 \\
\hline \multirow{2}{*}{ Totaal } & 26.8 & 30.3 & 22.5 & 46 & 2294
\end{tabular}

Floristisch en faunistisch behoort het grootste gedeelte van Suriname tot het oerwoudgebied van de Amazonevallei, een gebied dat, wat de verscheidenheid van vormen aangaat, boven alle andere uitmunt.

Het Landbouwproefstation ligt iets buiten de stad Paramaribo in den Cultuurtuin, waar hoofdzakelijk economisch belangrijke planten als cacao-, koffie-, suikerrietvarieteiten, rubbersoorten, vruchtboomen, vezelplanten en andere nuttige gewassen worden gekweekt. De tuin, die ongeveer 50 hectaren groot is, grenst direct aan het oerbosch. Van het Landbouwproefstation uit kan dus de flora en de fauna van het lage kustland gemakkelijk onderzocht worden.

We vinden hier boomen als Possentrie (Hura crepitans), Kankantrie (Ceïba pentandra), Inga-soorten, de eigenaardige Couroupita surinamensis, dan den mierenboom, Triplaris surinamensis, die altijd mieren in zijn holten bergt, en Cecropia peltata, eveneens een bekende mierenboom. Ook harde houtsoorten komen op de schulpritsen voor, als Bolletrie (Mimusops Balata), de boom die 
den bekenden Balata-rubber levert en Bijlhout of Walaba (Eperua falcata) met een harsrijk hout. Van palmen vinden we Bactris, de klimmende Desmoncus en Euterpe oleracea, de pinapalm, verder lianen als Paullinia, Mucuna, Passiflora, Cissus, Smilax, Paragonia, Clusia. In de kruinen der boomen groeien tal van epiphyten als Orchideën (Schomburgkia, Brassia, Oncidium, Rodriguezia, Jonopsis, Epidendrum), Cactaceen (Phyllocactus, Cereus triangularis, Rhipsalis), Tillandsien, Aechmea's, Gesneriaceen en varens (Polypodium, Dicranoglossum, Vittaria). Langs de kreken in de schaduw van het bosch staan Heliconia's, Montrichardia, Costus, Maranta, Ischnosiphon, Adiantum en op het water drijft de eigenaardige varen Ceratopteris thalictroides. Onder de mossen vinden we veel levermossen, vooral Frullania's. Naast een leger van Basidiomyceten groeien Phalloideën als Dictyophora en Mutinus, elegante Xylaria's, als Thamnomyces, talrijke bizarre Cordyceps-soorten en overal op de bladeren de interresante parasietische Asteroideae (roetdauw zwammen). Ook de fauna is hier zeer rijk vertegenwoordigd. De brulapen (Mycetes) komen hier tot in de nabijheid van de stad en evenzoo de Kwatta's (Atales) en de Kis-kissi's (Cebus). Onder de talrijke vleermuizen komen zeer groote bladneuzen (Phyllostomidae) en ook bloedzuigende vormen voor. We vinden hier den krabbenhond (Procyon), den jagoear (Felis onca), buidelratten of awari's (Didelphys), den luiaard met twee en ook die met drie teenen (Bradypus didactylus en tridactylus). Onder de hagedissen vinden we overal in de bewoonde streek de 3-4 voeten lange Sapacarra's (Tejus nigropunctatus) en Ameiva-soorten, in de boomen de wonderlijke Agama's (Polychrus marmoratus) en de grasgroene leguaan(Iguana). Onder de talrijke slangen zullen wij alleen de boa's en de ratelslangen noemen, die in de kuststreek niet zeldzaam zijn. In de slooten vinden we hier overal de kaaiman. In de zwampen achter den Cultuurtuin leeft de bekende Pipa americana, op de boomen zijn vele kikkers (Hyla, Dendrobates) en op vochtige plaatsen groote padden (bv. de geweldige Bufo marinus). Onder de talrijke 
visschen mogen we hier vooral de Callichthys (Siluridae), hier kwikwi geheeten, noemen. Langs de modderbanken van de Surinamerivier vinden we overal de zeer interessante vieroog (Anableps tetrophthalmus) en in geweldige massa's krabben (Uca una). Ook de insecten en spinnen zijn hier zeer rijk vertegenwoordigd. Onder de vlinders trekken onze aandacht vooral de schitterende azuurblauwe Morpho's. Zeer groot is het aantal mieren en termieten met nesten die, wat hun wonderlijke vormen aangaat, niet achterstaan bij de nesten van de eveneens talrijke bijen- en wespensoorten. Interessante mimicry vertoonen de roofzuchtige Mantissoorten en de grillige, staafvormige Phasmiden. In groote massa's vliegen s'avonds lichtkevers rond uit de families der Malacodermata en Elateridae. Van de spinnen, komt de groote boschspin (Mygale) algemeen voor. Van schelpdieren vinden we Ampullaria. Van de hier levende lagere dieren als wormen en protozoen, is nog zeer weinig bekend.

Buiten het Landbouwproefstation zijn er echter nog enkele andere plaatsen, die voor het inrichten van een tijdelijk laboratorium in aanmerking kunnen komen en wel:

Zanderij I

Sectie O

Kabelstation N

de Brownsberg

de Avanavero-vallen meerdere meters hooge watervallen, Kabalebo, Corantijn.

Zanderij I ligt 45 K.M. ten Zuiden van Paramaribo op een savanne. In het noordelijk gedeelte van Suriname zijn de savannen van edaphischen, niet van klimatischen oorsprong. Ze zijn meestal meer of minder dicht begroeid met lage heesters uit de families der Ternstroemeriaceae, Dilleniaceae, Myrtaceae, Malpighiaceae, Caesalpiniaceae, met kruiden als Schizaeaceae, Gramineae, Cyperaceae, Xyridaceae, Orchidaceae (Catasetum, Mormodes, Vanilla, Cyrtopodium, Galeandra), Polygalaceae etc. Deze sa- 
vannen staan gedurende den regentijd ten deele onder water. We vinden daarom op het witte kwartszand ook planten als Drosera, Utricularia en Sphagnum. Typisch voor de vochtige plaatsen op de savannen is ook de mooie Mauritie-palm (Mauritia flexuosa).

Van eigenaardige diervormen vinden we vooral het gordeldier, hier kapassi genoemd (Dasypus) en den grooten miereneter (Myrmecophaga jubata), die de talrijke termieten nesten in de savanne opzoekt. Onder de vogels vinden we de groote Ara-papagaaien (Ara ararauna en Ara macao) verder vele hagedissen en slangen. Voor den entomoloog vormen vooral de randen der savannen een waar dorado.

Sectie O, 65 K.M. ten Zuiden van Paramaribo, ligt in de eerste heuvelzone, met heuvels van 10-20 M. hoogte. Behalve een zeer kleine savanne vinden we hier vooral hoog bosch met boomen als groenhart (Andira), IJzerhart (Swartzia), Hevea guyanensis, met palmen, lianen en saprophyten uit de families der Gentianeae, Triuridaceae, Burmanniaceae en Balanophoraceae. Hier vinden we zeer talrijk de toekans of pepervreters (Ramphastos), die met hun luidruchtig gedoe en hun mooie kleuren en eigenaardige vormen zeer in het oog vallen. Herten (Cervus simplicicornis) en hun begeleiders de jagoears (Felis onca en Felis concolor) komen hier veelvuldig voor. De tapir (Tapirus), in de Kolonie buffel genoemd, is hier niet zeldzaam en de wilde varkens of pingo's (Dicotyles labiatus) kan men hier in troepen van over 100 individuen tegen komen. Sectie O kan 3 keer per week met den trein bereikt worden en is telefonisch met Paramaribo verbonden. Het huis van het Boschwezen is kleiner, dan dat op Zanderij I, maar heeft twee muskietenvrije kamers en een goede veranda. Daar Sectie $O$ reeds in de malariazone ligt, moet men hier zorg dragen, na zonsondergang achter de klamboe of in de muskietenvrije kamers te zijn.

Kabelstation N, 133 K.M. ten Zuiden van Paramaribo is bijzonder geschikt voor het biologisch onderzoek van de binnenlanden. Van hier uit kunnen de Diëti-vallen en de 
BIOLOGISCH ONDERZOEK IN SURINAME.

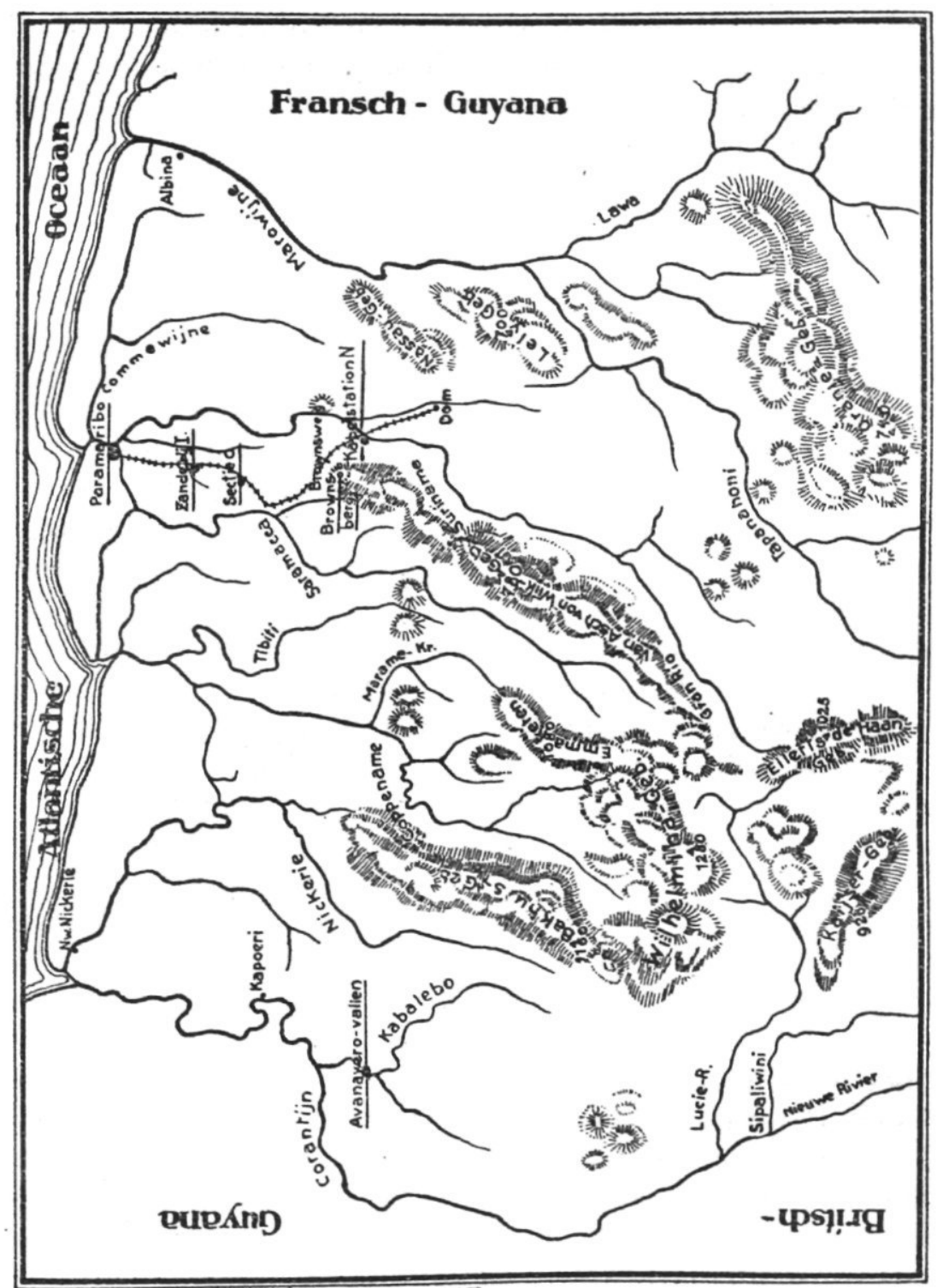


stroomversnellingen van Wakibasoe binnen $20-30 \mathrm{~min}$. per korjaal bereikt worden. Het is hier vooral de Podostemonaceeënflora (Mourera fluviatilis, Oenone spec. en Apinagia spec.) die den bioloog zal interesseeren. De zoöloog vindt een rijke waterfauna, mooie schelpen (Melania's), zoetwatersponzen, die hier nog niet nader onderzocht zijn, verder een groot aantal vischsoorten, daaronder de ook voor den mensch zeer gevaarlijke roofvisch Serrasalmo piraya, hier piring genoemd. In de kreken komt de sidderaal (Gymnotus electricus) voor. Ook voor grootere riviertochten is Kabelstation een geschikt uitgangspunt, b.v. naar de $2 \frac{1}{2}$ dag verder gelegen Mussoembapratti- en Mammadam-vallen. Het logeergebouw van het Gouvernement is hier zeer ruim, met groote muskietenvrije veranda's en vier ruime kamers, met telefoon, badkamer, keuken, W.C. en omvangrijke watertanks. Kabelstation kan één keer per week van uit Paramaribo per trein bereikt worden en heeft sinds 1919 een volledig meteorologisch termijnstation. Van de $26 \mathrm{M}$. hooge kabeltoren uit heeft men een fraai vergezicht op het omliggende oerbosch en de nabij gelegen bergen. Kabelstation ligt $19 \mathrm{M} . \mathrm{b} / \mathrm{z}$.

Zanderij I, Sectie O en Kabelstation N zijn uitsluitend door het noodige personeel van den spoorweg en het Boschwezen bewoond. De bedienden en alle levensmiddelen moeten daarom van Paramaribo meegenomen worden. Daar echter het vervoer per spoor kan geschieden, zijn de transportkosten relatief gering. Anders staat het met den Brownsberg en de Avanavero-vallen. Deze plaatsen kunnen niet met behulp van een koloniaal vervoermiddel bereikt worden. De kosten, die met een reis naar deze twee plaatsen verbonden zijn, zijn daarom aanmerkelijk hooger en kunnen ook wegens het primitieve onderkomen op deze plaatsen in 't algemeen slechts voor een bezoek van $1-2$ weken in aanmerking komen.

De Brownsberg, $420 \mathrm{M}$. b/z., is van het treinstation Brownsweg (115 K.M. ver van Paramaribo) in 3-4 uren - van Paramaribo uit dus in 1 dag - te bereiken. Het paadje loopt eerst door laag, in den regentijd vrij moeras- 
sig terrein en bereikt na één uur den voet van het bergland. Het eenvoudige afdak van het Boschwezen biedt plaats voor $3-5$ hangmatten en een tafel (zie de photo). Van uit den Brownsberg geniet men een prachtig vergezicht over de onmetelijke oerbosschen van noordelijk Suriname. De Brownsberg met zijn weelderigen plantengroei, met zijn grooten rijkdom aan varens (boomvarens en talrijke Hymenophyllaceae) en lianen, en met zijn bergbeekjes, die dikwijls over $10-20 \mathrm{M}$. hooge rotswanden zich in de diepte storten, geeft ons een goed beeld van het schilderachtige en bekoorlijke bergland van Suriname. Bergen van deze hoogte zijn anders in Suriname slechts na een reis van meerdere dagen of weken te bereiken. De Brownsberg vormt het einde van het Van Asch van Wijck gebergte, dat zich ver naar het Noorden uitstrekt, en juist nabij den spoorweg eindigt.

Bij de meerdere meters hooge Avanavero-vallen is het vooral de Podostemonaceeënflora (Oenone etc.), die hier in overweldigende pracht tot ontwikkeling komt. Wat we bij Kabelstation, in het klein zien, dat vertoont zich hier in het groot. Daar we hier ver verwijderd zijn van vaste woonplaatsen van menschen komen hier ook de hoogere dieren nog zeer veelvuldig voor; apen, tapir's, otters (Lutra brasiliensis), pingo's (Dicotyles labiatus), pakira's (Dicotyles torquatus), powiesen (Crax alector), kamikamis (Psophia crepitans), de zeldzame, eigenaardige Hoatzins (Opisthocomus Hoazin), sidderalen (Gymnotus electricus) en de stekelrog (Potamotrygon). De weg naar deze vallen is vrij lang: 1 dag per koloniale stoomer naar Nieuw-Nickerie, dan 1 dag per rivierboot naar Kapoerie en van daar in $1 \frac{1}{2}-2$ dagen per korjaal naar de Avanaverovallen in de Kabalebo, waar over eenigen tijd een kamp van het boschwezen gebouwd zal worden.

Met het Treub-Laboratorium te Buitenzorg kan en wil ons Surinaamsch Vreemdelingen-Laboratorium niet concurreeren. In verhouding tot het mooie en modern ingerichte Treub-Laboratorium zijn onze werkplaatsen hier vrij armoedige verschijningen. Onze bibliotheek is in verhouding tot die ginds weinig omvangrijk. De bioloog mist 
bij ons den mooien plantentuin dien hij te Buitenzorg vindt, mist ook grootendeels de uitvoerige inlichtingen, die hem de literatuur en de talrijke wetenschappelijke ambtenaren te Buitenzorg op biologisch gebied kunnen verstrekken; wegen om zich gemakkelijk per auto te verplaatsen, ontbreken buiten Paramaribo bijna geheel; het eenige treintje rijdt slechts één keer per week tot aan het eindpunt door en de 2-3 hotels in Paramaribo zijn zeer eenvoudige inrichtingen. Maar daartegenover biedt Suriname aan den vreemdeling een buitengewoon rijke flora en fauna, zooals hij ze nauwelijks elders kan vinden.

Ten slotte mogen wij er misschien ook nog op wijzen, dat de reis van uit Holland ongeveer 1 week korter duurt, dan die naar Java en dat ook de kosten voor den overtocht belangrijk lager zijn.

Hoewel heden Suriname niet meer de op natuurwetenschappelijk gebied „zoo verwaarloosde” kolonie van 1896 is, zoo is toch met het onderzoek van ons rijk land pas een begin gemaakt.

We hopen zeer, dat het bovenstaande dezen of genen bioloog zal bewegen, om voor enkele maanden in Suriname te komen werken. De ondergeteekenden zullen hem gaarne alle gewenschte inlichtingen verschaffen en hem bij zijn werk in Suriname allen steun verleenen, voor zoover dit in hun macht staat.

De hieronder opgesomde boeken en tijdschriften stellen den bioloog, die Suriname wenscht te bezoeken, in staat, om zich over ons land en zijne flora en fauna te orienteeren.

Encyclopaedie van Nederlandsch West-Indië, door Dr. H. D. Benjamins en Joh. F. Snelleman, 's Gravenhage, 1914-1917.

Surinaamsche Almanak „De Vraagbaak”, Paramaribo, 1918.

Overzichtskaart van Suriname, schaal $1: 800.000,1913$.

Kaart van Paramaribo en omstreken, schaal $1: 25.000$, 1907.

West-Indische Gids, Amsterdam/'s Gravenhage. 
Timehri, The Journal of the Royal Agricultural and Commercial Society of British Guiana, Georgetown.

Koloniaal Museum te Haarlem. Bulletins van het -

Boletim de Museu Paraense. s. Goeldi, Para.

Revista do Museu Paulista, Sao Paulo.

Aublet, J. B. Histoire des plantes de la Guyane française. Paris, 1775.

Pulle $A$. An enumeration of the vascular plants known from Surinam, Leiden, 1905.

Pulle A. Zakflora van Suriname, 1e gedeelte Bull. van het Kol. Mus. te Haarlem, No. 47, Amsterdam, 1911.

Pulle A. Beiträge zur Flora Surinams I, II, III Recueil des travaux bot. Neerlandais, 1908, 1909, 1912.

Went, F. A. F. C. Untersuchungen über Podostemonaceen; Verhandelingen der Kon. Akad. van Wetenschappen te Amsterdam, 2e Sectie, Deel XVI, No. 1.

Kappler, A. Surinam, sein Land und seine Natur, Bevölkerung und seine Kulturverhältnisse, Stuttgart, 1887. (In dit werk vindt men een overzicht van de fauna).

Penard, F. P. en A. Ph. De vogels van Guyana, Paramaribo, $1908-1910$.

Martin, $K$. Bericht über eine Reise nach Niederl. WestIndien und darauf gegründete Studien. Leiden, 1888.

Dubois, G. C. Geologisch bergmannische Skizzen aus Surinam. Freiberg, 1901.

Harrison, $J$. B. The Geology of the Goldfields of BritishGuiana London, 1908.

Cappelle, H. van. Essai sur la constitution géologique de la Guyane Hollandaise. Baarn, 1907.

Schomburgk, Rich. Reisen in Britisch-Guyana in den Jahren 1840-1844. Leipzig, 1848.

Nickerie-Expeditie H. van Cappelle, Tijdschr. v/h. Kon. Ned. Aardr. Genootschap 1903.

Coppename-Expeditie, L. A. Bakhuis, idem 1902.

Saramacca-Expeditie, A. J. van Stockum, idem 1904.

Gonini-Expeditie, A. Franssen-Hederschee, idem 1905.

Tapanahoni-Expeditie, A. Franssen-Herderschee, idem 1905.

Toemoek-Hoemak-Expeditie, C. H. de Goeie, idem 1908. 
76 EEN VREEMDELINGEN-LABORATORIUM IN SURINAME.

Suriname-Expeditie, J. G. W. J. Eilerts de Haan, idem 1910.

Corantijn-Expeditie, C. C. Kayser, idem 1912.

Ten slotte mogen nog enkele opgaven volgen, die het mogelijk maken, de onkosten van een reis naar Suriname ongeveer te berekenen.

Amsterdam-Paramaribo $f \in 00$ - - , (vroeger retour 1 jaar $f \in 00 .-$, enkele reis $f 400$.- ).

Amsterdam-Batavia $f$ 1200.-, (vroeger $f$ 750.-).

Hotelkosten te Paramaribo per dag $f$ 6.50.

Loon voor boscharbeiders en reisbedienden $f 2$.- (incl. voeding).

Loon voor boschnegers per dag (Suriname-rivier) $f 3.50$ (incl. voeding).

per trein van Paramaribo naar Zanderij I $f 1.30$

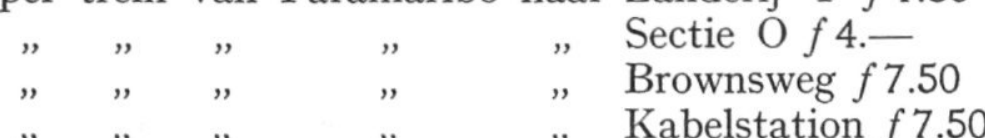

" Koloniale stoomboot van "Paramaribo naar Nw. Nickerie $f$ 11. -

rivierboot van Nw. Nickerie naar Kapoerie $f$ 4.-

huur van een korjaal of visschersboot per dag $f 0.50$ tot $f 1$.-

1 singaporetropen-pak te Paramaribo $f$ 18. - tot $f$ 20.wasch per pak $f 0.30$

" $\quad$ stuk ondergoed $f 0.10$.

Paramaribo, Januari 1920. 